\title{
DESVIOS MORFOLÓGICOS NO SATYRICON, DE PETRÔNIO: SINCRETISMO CASUAL E ESTIGMA LINGÜÍSTICO NO SÉC. I D.C.
}

\author{
Sandra Maria Gualberto Braga Bianchet ${ }^{\star \star}$
}

\begin{abstract}
Resumo: $O$ objetivo deste artigo é apresentar dados sobre a redução do número de paradigmas temáticos no latim do séc. I d.C., utilizando como objeto de estudo a obra Satyricon, de Petrônio. A análise, feita a partir da listagem dos nomes que apresentam alteraçōes formais características do sincretismo casual, aponta para o uso, pelo autor, dessas formas como meio de demarcar a escolaridade dos falantes.
\end{abstract}

\section{Introdução}

As línguas indo-européias antigas, grupo do qual o latim faz parte, são todas elas de tipo marcadamente flexional e caracterizam-se por apresentar um sistema lingüístico em que as relações sintáticas entre os membros do enunciado se expressam quase que exclusivamente (senão exclusivamente) através do recurso morfológico dealteração na forma da palavra em função do papel sintático que a mesma desempenha na frase. Essas alterações formais podem ser internas (alternância de tom e alternâncias vocálicas), ou externas (emprego de desinências) (MONTEIL, 1970:122-3).

\footnotetext{
- Recebido para publicação em setembro de 2005.

* Professora da Faculdade de Letras/UFMG.
} 
Em latim, o emprego de alterações internas se limita a alguns casos raros de alternâncias vocálicas de timbre (como no nome próprio Aniō - Aniēnis) e, em maior número, traços de alternâncias vocálicas de quantidade (ex.: homō - homĭnis), sempre acrescidas de alterações externas. As alterações com base em alternâncias de tom não deixaram qualquer vestígio em latím, que desde uma época pré-histórica apresenta tom fixo (ERNOUT, 1953:10-11). A morfologia nominal latina é marcada por alterações formais externas, com o emprego de desinências, que trazem em si as informações relativas às categorias gramaticais de caso, número e gênero que um determinado vocábulo expressa ${ }^{1}$. O quadro de agrupamentos de alterações morfológicas é composto a partir da combinação entre as diversas subdivisões de cada categoria (casos nominativo, vocativo, acusativo, genitivo, dativo e ablativo; números singular e plural; gêneros masculino, feminino e neutro) e integra cinco paradigmas, definidos em função de características morfológicas comuns presentes no tema do vocábulo (TAGLIAVINI, 1962:128; IVO et al., 1987:27).

Esse complexo sistema morfológico está presente no latim clássico e apresenta algumas modificações em relação ao sistema indo-europeu de que se origina. Além da supracitada redução do número de mecanismos flexionais de alterações formais internas, destacam-se, comoimportantes modificações, a reunião dos casos ablativo, locativo e instrumental em uma mesma forma (sincretismo), que recebe o nome do primeiro;

1 Apesar de o paradigma de tema em -a (1 ${ }^{\text {a }}$ declinação) apresentar a alternância de quantidade como única marca de diferenciação entre nominativo singular (-a final breve) e ablativo singular (-a final longo), historicamente também esta diferenciação se fazia por um oposição externa: ausência de desinência de caso para o nominativo e acréscimo da desinência - $\mathrm{d}$ em ablativo.

2 O locativo em latim sobrevive apenas em algumas expressōes fixas (como por exemplo domî, rurī e em nomes de cidades e pequenas ilhas), que são consideradas como um tipo de advérbios, uma vez que não admitem aposto, ou complemento adnominal (ERNOUT, 1953:11-13). 
e a eliminação do número dual como parte do paradigma da categoria de número ${ }^{3}$.

A simplificação do sistema flexional é uma característica comum a todas as línguas indo-européias e se caracteriza como um reflexo da tendência a se eliminar a complexidade do sistema flexional e a se suprimirem as distinções tidas como supérfluas. Em latim, a eliminação do sistema sintético de marcação casual e de algumas categorias gramaticais nele expressas se implementa gradativamente, sendo este sistema sintético de base morfológica substituído por dois subsistemas analíticos auxiliares de base sintática: o uso de preposições e a fixação da ordem das palavras (DE DARDEL, 1990:92).

A fixação desses subsistemas analíticos e a redução do número de categorias gramaticais morfologicamente marcadas que se mantiveram nas línguas românicas em geral no lugar do sistema sintético, no entanto, são processos extremamente complexos e não se podem estabelecer com exatidão os caminhos que teriam sido percorridos até sua completa implantação nas línguas. Estes se encontram como que diluídos, fragmentados em algumas obras de alguns autores latinos, obras estas apontadas como fontes para o estudo dessas alterações morfológicas, como o Satyricon de Petrônio.

Nos muitos episódios do Satyricon, o narrador Encólpio, um estudante de Retórica, por diversas vezes, cede a vez e a voz a falantes de baixa escolaridade (escravos, libertos, mulheres), cuja fala é cuidadosa e deliberadamente marcada pelo autor através de desvios em relação à linguagem erudita do próprio narrador. Em vista disso, a obra de Petrônio pode ser considerada como uma fonte para o estudo da implantação desses subsistemas analíticos no séc. I d.C.

3 Vestígios das desinências de dual do indo-europeu podem ser encontrados em latim no cardinal dŭo, em $a m b \bar{o}$, que se declina como duŏ, e em uiginti, cuja desinência $-i$ se opõe à desinência $-a$ dos outros decimais (ERNOUT, 1953: 154157). 
Ao longo dos capítulos do Satyricon, depara-se com diversos e diversificados casos de desvios da morfologia nominal tida como padrão. Esses casos compreendem alterações na categoria de gênero (decadência do neutro, desinência - $a$ de plural neutro usada como feminino singular, mudança do gênero da palavra) e alterações na categoria de caso (formação analógica do nominativo, confusão na atribuição de casos, uso de formas analíticas pelas sintéticas, troca de declinação, desaparecimento da $4^{\mathrm{a}}$ e da $5^{\mathrm{a}}$ declinação). Mais especificamente em relação às alterações na categoria de caso, observa-se o emprego das formas alteradas quase que exclusivamente na fala dos personagens pouco escolarizados, o que favorece a leitura de que o autor do Satyricon esteja, de fato, demarcando para o leitor que o registro de linguagem ali usado é característico dos falantes que ocupam determinada posição na escala social.

\section{Alterações na categoria de caso}

As alterações na categoria de caso em relação ao latim clássico que caracterizam a linguagem popular envolvem dois grandes processos lingüísticos que afetam a língua latina em sua totalidade: a redução do número de casos de seis para dois ${ }^{4}$ e do número de paradigmas temáticos (grupos de desinências casuais) de cinco para três.

A redução do número de paradigmas temáticos decinco para três envolveu a eliminação das formas dos temas em - $u$ $(-u s /-u,-u s)$ e em -e (-es, -ei), cujas palavras passaram a assumir as formas dos temas que se mantiveram, em sua maioria do

\footnotetext{
A redução no número de casos apresenta no Satyricon um volume mais reduzido de dados, apesar de significativos. Em função disso, optou-se, neste artigo, por detalhar a análise apenas dos dados relativos ao sincretismo casual. Remete-se o leitor interessado em ter acesso aos dados de redução do número de casos a BIANCHET (2002).
} 
tema em $-o(-u s /-u m,-i)$ e em $-a(-a,-a e)$, respectivamente, e em número mais reduzido também do tema em - $i$ /consoante. Em termos funcionais, o ponto de partida para essa transferência parece ter sido o pequeno número de palavras pertencentes aos temas eliminados (FARIA, 1995:109; CART et al., 1986:21), insuficiente para justificar a manutenção de mais dois paradigmas temáticos. Além disso, a identidade existente entre algumas formas dos temas em -o e em $-u$ (nominativo singular -us e acusativo singular -um) e a duplicidade de temas de algumas palavras (do tipo materies/materia), já prevista desde a base de formação desses vocábulos, pela existência do sufixo -ia como forma alternativa para o sufixo -ies, parecem ter atuado de forma a acelerar essa transferência. A partir dessas formas duplas, com o predomínio das pertencentes aos temas em - $a$ e em $-o$, a alteração se estendeu a praticamente todas as palavras de tema em $-u$ e em $-e$, que desapareceram na linguagem popular de fins do império (FARIA, 1995:109). O tema em -i/consoante, apesar de se ter mantido, sofreu algumas alterações, principalmente no que se refere à normalização de algumas formas de nominativo singular que tinham aspecto de anomalia. Tal normalização se efetuou através de formações analógicas, algumas vezes com mudança de tema (do tipo strix-tema em consoante, que passa a striga, tema em $-a$ ), outras vezes dentro do próprio tema em $-i$ /consoante (ex.: Iouis, como nominativo singular, ao lado de Iuppiter).

\section{Listagem das alterações no quadro de paradigmas temáticos}

As alterações no quadro de paradigmas temáticos se encontram organizadas em dois quadros: um que lista as alterações ocorridas dentro do mesmo tema, outro que lista 
alterações com mudança de tema; ambos os quadros estão subdivididos em duas colunas, das quais a primeira traz a forma padrão, tal como indicada no dicionário, em ordem alfabética, com sua respectiva tradução na(s) acepção(ções) utilizadas por Petrônio, seguida das ocorrências no Satyricon relevantes para se estabelecer a oposição com a forma alterada, e a segunda traz a forma alterada, no mesmo formato da dicionarizada (forma plena do nominativo singular, acompanhada da desinência de genitivo singular e do gênero, caso se trate de substantivo), seguida $\mathrm{da}(\mathrm{s})$ ocorrência(s) presente(s) no Satyricon. Todas as ocorrências listadas apresentam a devida indicação do capítulo e subdivisão do capítulo do texto em que as mesmas se encontram. Ao final de cada quadro, indica-se o número de ocorrências de formas alteradas em cada um dos grupos de episódios do Satyricon.

\section{A) ALTERAÇÕES NO QUADRO DE PARADIGMAS TEMÁTICOS}

A.1- Sem mudança de tema

\begin{tabular}{|c|c|}
\hline FORMA PADRÃO & FORMAALTERADA \\
\hline 1-Bos, bouis (m): "boi" & $\begin{array}{l}\text { Bouis, bouis (m) } \\
\text { Bouis }(62,13)-\text { nom. sing. }\end{array}$ \\
\hline 2- Excellens, -entis: "excelente" & $\begin{array}{l}\text { Excellens, excellente } \\
\text { Excellente }(45,4) \text { - acus. sing.; }(66,3)- \\
\text { nom. sing. }\end{array}$ \\
\hline 3- Lac, -tis (n): "leite" & $\begin{array}{l}\text { Lacte, -tis (n) e lactis, -tis (m) } \\
\text { Lacte }(38,1) \text {-acus. sing; lactem }(71,1)\end{array}$ \\
\hline $\begin{array}{l}\text { 4- luppiter, louis (m): "Júpiter" } \\
\text { luppiter }(22,5)(83,4)(122,1,140) \\
(123,1,206)(123,1,241)(126,18, \\
\text { 1) }(127,9,3)\end{array}$ & $\begin{array}{l}\text { louis, -is }(\mathrm{m}) \\
\text { louis }(47,5)(58,2) \text { - nom. sing. }\end{array}$ \\
\hline $\begin{array}{l}\text { 5- Sanguis, } \text {-inis (m): "sangue" } \\
\text { Sanguis }(124,1,270)\end{array}$ & $\begin{array}{l}\text { Sanguen, -inis (m) } \\
\text { Sanguen }(59,1)\end{array}$ \\
\hline 6- Stipes, -itis (m): "estúpido" & $\begin{array}{l}\text { Stips, stipis (m) } \\
\text { Stips }(43,5)\end{array}$ \\
\hline 7- Volpes, -is (f): "raposa" & $\begin{array}{l}\text { Volpis, -is (f) } \\
\text { uolpis }(58,12)-\text { nom. sing. }\end{array}$ \\
\hline
\end{tabular}


episódios iniciais (1-26): 00 episódios da Cena (27-78): 11 episódios finais (79-141): 02

\section{A.2- Com mudança de tema}

\begin{tabular}{|c|c|}
\hline FORMA PADRÃO & FORMA ALTE RADA \\
\hline $\begin{array}{l}1 \text { - Deus, }- \text { i (m): "deus" } \\
\text { Diis }(58,14)(114,8)(115,16)\end{array}$ & $\begin{array}{l}\text { Deus, -us }(m) 5 \\
\text { Diibus }(44,16) \text { - ablativo plural }\end{array}$ \\
\hline $\begin{array}{l}\text { Discolor, } \\
\text { diferentes }\end{array}$ & $\begin{array}{l}\text { Discolorius, }-\mathrm{a},-\mathrm{um} \\
\text { Discoloria }(97,3)-\mathrm{abl} \text {. sing. }\end{array}$ \\
\hline $\begin{array}{rrr}\text { 3- } \text { Gustus, } & \text {-us } \begin{array}{r}\text { (m): "aperitivo, } \\
\text { entrada, amostra" }\end{array}\end{array}$ & $\begin{array}{l}\text { Gustus, }-i(m) / \text { gustum, }-i(n) \\
\text { Gusti }(76,5)-\text { gen. sing. }\end{array}$ \\
\hline $\begin{array}{l}\text { 4- Lampas, -adis (f): "tocha" } \\
\text { Lampada }(124,1,277)\end{array}$ & $\begin{array}{l}\text { Lampada, -ae }(\mathrm{f}) \\
\text { Lampadas }(124,1,284)\end{array}$ \\
\hline 5- Palumbes( -is), -is (m): "pombo" & $\begin{array}{l}\text { Palumbus, }-\mathrm{i}(\mathrm{m}) \\
\text { Palumbum }(70,2)\end{array}$ \\
\hline $\begin{array}{l}\text { 6- Schema, -atis (n): "colocação, } \\
\text { rodeio (ao falar)" } \\
\text { Schema }(126,8)\end{array}$ & $\begin{array}{l}\text { Schema, -ae (f) } \\
\text { Schemas }(44,8)\end{array}$ \\
\hline $\begin{array}{c}\text { - Stigma, -atis }(n): \text { "marca, estigma, } \\
\text { marca de ferro em } \\
\text { brasa" } \\
\text { Stigmate } \begin{array}{r}(103,2), \\
11)\end{array}\end{array}$ & $\begin{array}{l}\text { Stigma, -ae (f) } \\
\text { Stigmam }(45,9)(69,2)\end{array}$ \\
\hline $\begin{array}{l}\text { 8- Strix, -gis (f): "bruxa, feiticeira" } \\
\text { Striges }(134,1)\end{array}$ & $\begin{array}{l}\text { Striga, } \text {-ae (f) } \\
\text { Strigae }(63,4)(63,8)\end{array}$ \\
\hline $\begin{array}{l}\text { 9- Trimalchio, } \\
\text { "Trimalquião" } \\
\text { Trimalchionem }(74,9)\end{array}$ & $\begin{array}{l}\text { Trimalchius, }-i(m) \\
\text { Trimalchium }(72,4)\end{array}$ \\
\hline 10-Vas, uasis (n): vaso & $\begin{array}{l}\text { Vasum, }-i(n) / \text { uasus, }-i(m) \\
\text { Vasum }(50,3) \text {, uasus }(57,8)\end{array}$ \\
\hline
\end{tabular}

episódios iniciais (1-26): 00 episódios da Cena (27-78): 11 episódios finais (79-141): 02

5 Apesar de o ablativo em -bus poder igualmente ser associado ao paradigma de tema em - $i$ /consoante, optou-se pela forma hipotética seguindo o paradigma de tema em -u, em função da identidade entre as formas de nominativo singular dos dois temas. 


\section{Análise dos dados}

As alterações no quadro de paradigmas temáticos foram subdivididas em dois grupos: alterações dentro do próprio tema e alterações com mudança de tema.

Oquadro A.1, quelista as formas que sofreramalterações dentro do próprio tema, é todo ele composto por palavras de tema em -i/consoante, cujo nominativo singular padrão apresenta algum tipo de anomalia, que permita a identificação direta entre o tema do nominativo singular e o do genitivo singular, que serve de base para formação dos demais casos (como, por exemplo, o acréscimo do item lexical pater ao tema Iou- e queda da consoante temática em nominativo). A forma "anômala" de nominativo é, então, substituída por outra, formada em analogia com um dos paradigmas de tema em -if consoante considerado mais regular. Tais formações analógicas representam a tendência a se eliminarem formas que não se constituem propriamente em paradigma, pois que em geral se aplicam a um único vocábulo, em favor de paradigmas já existentes dentro do tema em $-i$ /consoante, substituindo "exceções" por formas tidas como "regulares". As formas stips e uolpis (ocorrências 6 e 7) se diferenciam das demais por serem formações analógicas feitas a partir de outras formas de nominativo de tema em $-i$ /consoante (do tipo princeps, principis e ciuis, ciuis, respectivamente). As demais formas eliminam a "anomalia" através da criação de formas análogas de nominativo dentro de seu próprio paradigma, a partir do genitivo, que passa a servir de base para formação de todos os casos, sem exceção. Para GRANDGENT (1952:227), essa é uma tendência da linguagem popular que teria tido como ponto de partida formas como bouis, lacte/lactem, Iouis e sanguen, em que o genitivo apresenta o acréscimo de uma sílaba, em relação à forma de nominativo padrão, sem mudar a sílaba tônica (sanguis, sanguinis); somente depois, ter-se-ia estendido para 
as formas em que há mudança de sílaba tônica, como em excellens - excellente. VÄÄNÄNEN (1985:191) analisa a forma excellente como um "caso isolado" em Petrônio. A análise dos dados listados em A.1 confirma a afirmação de que esta seria uma tendência popular, uma vez que todas as formas alteradas ocorrem exclusivamente nos episódios da Cena (capítulos 27 a 78) e, quando há a co-ocorrência de formas padrão e alterada, existe uma diferenciação nítida de emprego por grupo de episódios: a forma padrão ocorre nos episódios iniciais e/ou finais (Iuppiter, sanguis), enquanto a forma alterada se restringe aos episódios da Cena (Iouis, sanguen).

O quadro A.2, por sua vez, é composto por palavras de temas variados, que têm em comum uma alteração de todo o paradigma temático de que faz parte a forma padrão. Observa-se que, na maioria dos casos (itens 2, 4, 5, 6, 7, 8, 9 e 10), a alteração se processa com a transposição de palavras de tema em $-\mathrm{i}$ /consoante para os temas em -a e em -o. As demais alterações (itens 1 e 3 ) envolvem os temas em -o e em -u, mas representam processos inversos: mudança de paradigma de -o para em - $u$ (diibus por diis) e de -u para -o (gusti por gustus).

Pelo quadro exposto acima, essas alterações não caracterizam a redução dos paradigmas temáticos de cinco para três (eliminação dos paradigmas de tema em -u e em -e), uma vez que:

a) não há formas alteradas de tema em -e;

b) a ocorrência de uma única forma alterada de tema em -u para o tema em -o não é suficiente para que se fale em processo de mudança, especialmente porque o texto traz a forma diibus que faz o movimento contrário ${ }^{6}$.

6 Para ERNOUT (1914: 51), essa forma é um "barbarismo", criado a partir da forma deabus. 
Por outro lado, os dados mostram que, antes que houvesse a reorganização da classe nominal em três paradigmas temáticos, a reorganização atingiu o tema em -i/ consoante, que teve alguns de seus vocábulos "transferidos" para os temas em -a e em - 0 , transferência condicionada por fatores morfológicos, a saber:

a) força da desinência -a como marcadora de nominativo singular (lampadas, schemas, stigmam, strigae $^{7}$;

b) força da desinência - $u m$ como marcadora de neutro e -us como marcadora de masculino (uasus/uasum, Trimalchium).

Também no quadro A.2 pode-se encontrar uma relação entre o uso de formas alteradas e os grupos de episódios do Satyricon, qualseja, as formas alteradas ocorrem principalmente nos episódios da Cena e, para algumas formas, existe a mesma diferenciação de emprego por grupo de episódios identificada acima (forma padrão nos episódios iniciais e/ ou finais - schema, stigmate/stigmata, striges; forma alterada restrita aos episódios da Cena - schemas, stigmam, strigae).

\section{Conclusão}

As alterações morfológicas em relação à norma clássica relativas ao sistema de declinação no Satyricon podem ser analisadas como uma demonstração de que a morfologia é um recurso de que Petrônio lança mão para marcar os diferentes

7 As formas lampadas, schemas, stigmam já possuíam a desinência -a em seu paradigma (lampada - acusativo singular, schema e stigma - nominativo singular neutro), o que justifica a transferência para a primeira declinação; a criação da forma strigae, por sua vez, é motivada pela associação direta entre gênero feminino e tema em $-a$. 
níveis de fala de uso corrente na sociedade romana retratada em sua narrativa. A diferenciação de emprego das formas populares, eruditas e clássicas se encontra bem marcada nos três grupos de episódios: a morfologia nominal clássica prevalece nos episódios iniciais, a popular é reservada aos capítulos da Cena, a erudita faz parte dos episódios finais.

$O$ estudo dos desvios presentes na morfologia do Satyricon em relação à norma clássica demonstra que há uma distinção importante no emprego de formas padrão e coloquial, já no séc. I de nossa era. Caracteriza, outrossim, que as alterações da morfologia nominal se constituíam em meio de estigmatizar a linguagem das classses sociais menos instruídas dos grupos sociais representados na obra e pode ser interpretado como um dos raros momentos que a literatura clássica nos legou, em que o latim falado, o registro coloquial que deu origem às línguas românicas, se mostra tão abertamente.

Résumé: L'objectif principal de cet article est de présenter des informations sur la réduction du nombre de paradigmes thématiques du $1^{\text {tr }}$ siècle après $J .-C$., en utilisant comme objet d'étude l'oeuvre Satyricon, de Pétrone. L'analyse, faite à partir d'une liste établie de noms qui portent des altérations formelles caractéristiques du synchrétisme casuel, montre quie l'auteur emploie ce type de formes comme un moyen de marquer le niveau d'instruction des personnages.

\section{Referência bibliográfica}

BIANCHET, S.M.G.B. "Satyricon, de Petrônio: estudo lingüístico e tradução". tese de doutoramento. São Paulo: FFLCH/USP, 2002. 
BYNON, T. Historical linguistics. Cambridge: Cambridge University Press. 1977.

CÂMARA JR, J. M. Dicionário de filologia e gramática. $3^{\mathrm{a}}$ ed. rev. e aum. Rio de Janeiro: J.Ozon + Editor, 1968.

- Princípios de lingüística geral. $4^{\mathrm{n}}$ ed. rev. e aum. Rio de Janeiro: Livraria Acadêmica, 1969.

CART, A. et al. Gramática latina. Tradução e adaptação de Maria Evangelina Villa Nova Soeiro. São Paulo: T.A. Queiroz: Ed. da Universidade de São Paulo, 1986.

DE DARDEL, $R$. "Remarques sur la simplification morphologique en latin oral". In: CALBOLI, G. (org.) Latin Vulgar - latin tardif II. Actes du II ${ }^{\mathrm{eme}}$ Colloque International sur le latin vulgaire et tardif. Tübingen: Max Niemeyer Verlag, 1990.

ERNOUT, A. Les Éléments dialectaux du vocabulaire latin. Paris: Librairie Ancienne Honoré Champion, 1928.

. Morphologie historique du latin. $3^{\mathrm{eme}}$ éd. rev. et corr. Paris: C.Klincksieck, 1953.

ERNOUT, A. \& THOMAS, F. Syntaxe latine. - 2a ed. rev. e aum. - Paris: Librairie C. Klincksieck, 1953.

FARIA, E. Fonética histórica do latim. $2^{\mathrm{a}}$ ed. rev. e aum. Rio de Janeiro: Livraria Acadêmica, 1957.

. Dicionário escolar latino português. $3^{\text {a }}$ ed. Rio de Janeiro: MEC, 1962.

. Gramática da lingua latina. revisão de Ruth Junqueira de Faria - 2a ed. rev. e aum. - Brasília: FAE, 1995. 
FORCELLINI, AEGIDIO. Lexicon totius latinitatis. PATAVII TYPIS SEMINARII, 1940.

GAFFIOT, F. Dictionnaire latin français. Paris: Hachette, 1934.

GIACOMELLI, ROBERTO. Storia della lingua latina. Roma: Jouvence Società Editoriale, 1993.

GRANDGENT, C. H. Introducción al latín vulgar. Traducción del ingles, adicionada por el autor, corregida y aumentada con notas, prologo y una antología por Francisco de B. Moll. Madrid: Selecciones Gráficas, 1952.

GUARDIA, J.M. \& WIERZEYSKI, J. Grammaire de la langue latine. $4^{\text {a }}$ ed. Paris: A. Durand et Pedone-Lauriel, Éditeurs, 1876.

HERRERO, VÍCTOR JOSÉ. Introducción al estudio de la filología latina. $2^{\mathrm{a}}$ ed. ( $1^{\mathrm{a}}$ reimpressão). Madrid: Editorial Gredos S.A., 1981.

IVO, O.S. et al. Latim fundamental. Belo Horizonte: Editora da UFMG/PROED, 1987.

KIECKERS, ERNST. Historische lateinische Grammatik: Lautlehre. München: Max Hueber Verlag, 1960.

LAVENCY, MARIUS. VSVS - Grammaire latine. Paris: Duculot, 1985.

LEUMANN, M., HOFMANN, J. B., SZANTYR, A. Lateinische Grammatik / Laut- und Formenlehre (erster Band). München: C.H. Beck'sche Verlagsbuchhadlung, 1963.

. Lateinische Grammatik / Syntax und Stilistik (zweiter Band). München: C. H. Beck'sche Verlagsbuchhandlung, 1964. 
MARTINET, ANDRÉ. "Réflexions sur le 'neutre' indoeuropéen". In: BROGYANYI, BELA \& REINER, LIPP (org.): Current Issues in Linguistic Theory, 97: Comparative-Historical Linguistics: Indo-European and Finno-Ugric.. Amsterdam/ Philadelphia: John Benjamins Publishing Company, 1993.

MAROUZEAU, J. Traité de stylistique appliquée au latin. Paris: Société d'Édition "Les Belles Lettres", 1935.

. L'ordre des mots dans la phrase latine. Paris: Société d'édition "Les Belles Lettres", 1949.

Quelques aspects de la formation du latin littéraire.Paris: Librairie C. Klincksieck, 1949.

MAURER JR., T. H. Gramática do latim vulgar. Rio de Janeiro: Livraria Acadêmica, 1959.

MEILLET, A. Linguistique historique et linguistique générale. Paris: Librairie Honoré Champion, 1965.

MEILLET, ANTOINE \& VENDRYES, J. Traité de grammaire comparée des langues classiques. $4^{\text {a }}$ edição. Paris: Librairie Ancienne Honoré Champion, 1966.

MONTEIL, P. Éléments de phonétique et de morphologie du latin. Paris: Éditions Fernand Nathan, 1970.

PALMER, L. R. The latin language. London: Faber and Faber Limited, 1954.

PETRÓNE. Le Satiricon. texte ét. et trad. par A. ERNOUT. Paris: "Les Belles Lettres", 1999.

PETRÔNIO. Satyricon. tradução de Sandra Braga Bianchet. Belo Horizonte: Crisálida, 2004. 
PETRONIUS. Satyrica. trad. von Konrad Müller und Wilhelm Ehlers. München: Artemis Verlag, 1983.

SEGEBADE, I. \& LOMMATZSCH, E. Lexicon Petronianum. Hildesheim: Georg Olms Verlag, 1988.

TAGLIAVINI, CARLO. Fonetica e morfologia storica del latino. $3^{\mathrm{a}}$ ed. Bologna: Casa Editrice Prof. Ricardo Patrón, 1962.

VÄÄNÄNEN, V. Introducción al latín vulgar. Madrid: Editorial Gredos, 1985. 